\title{
Preventing Homelessness among Substance Users in Europe
}

\author{
Joe Doherty $\cdot$ Maria Stuttaford
}

Published online: 31 May 2007

(C) Springer Science+Business Media, LLC 2007

\begin{abstract}
Prior to the 1970s, neither homelessness nor drug addiction was seen as issues of major concern in Europe. At most, they were of local interest and of particular importance only in some larger metropolitan centres. Over the last three decades they have come much more into public prominence and risen up in local and national policy agendas. At the level of the European Union (EU), however, while the use and abuse of drugs has attracted substantial financial resources and institutional involvement, homelessness, in comparison, has been relatively neglected and remains predominantly the concern of non-government and voluntary organisations. At all three levels-local, national, and European-it is only in recent years that the link between homelessness and problematic substance use has come to the fore as an issue of singular concern. This paper examines the recent emergence of policies and programmes which seek to tackle and prevent homelessness among substance users. Our investigation suggests that although new initiatives at the EU level are limited, at the national and especially sub-national level, effective programmes addressing both treatment and prevention are being designed and implemented.
\end{abstract}

Keywords Homelessness - Substance misuse - Prevention · Partnership · Transferability

J. Doherty $(\bowtie)$

Centre for Housing Research, School of Geography, University of St. Andrews, Irvine Building, St. Andrews, Fife KY16 9AL, Scotland, UK

e-mail: jd@st-andrews.ac.uk

M. Stuttaford

Honorary Lecture in Geography, University of St. Andrews, St. Andrews, Fife, Scotland, UK 


\section{European Trends in Homelessness and Substance Misuse}

European trends in homelessness and substance misuse are uneven and changing, both temporally and spatially, and the relationship between them is complex. The monitoring of homelessness and substance use and misuse is notoriously problematic and methodologically challenging, not least because the definition of both concepts can vary from country to country as well as from research project to research project. To the extent that it has been possible to aggregate statistics from local and national data, recent estimates suggest that at the beginning of the new millennium, in the EU-15, ${ }^{1}$ some 18 million people experienced homeless (approximately 1 in 20), and 1.5 million (approximately 1 in 300) were problem drug users (European Monitoring Committee for Drugs and Drug Addiction (EMCDDA) 2005; European Union Working Group Report 2000). Since enlargement in 2004 the situation has not improved. Indeed, available evidence suggests that the addition of eight countries from Central and East Europe, especially, has compounded the problems of homelessness and substance misuse particularly as there has been no notable improvement in the 'old' European Union member countries. Notwithstanding the approximate nature of the data, all the available evidence indicates a serious level of homelessness and drug misuse among significant numbers of Europe's population.

According to the 2005 report of the European Monitoring Committee on Drugs and Drug Addiction (EMCDDA), polydrug use is now common in all EU countries and the measurement of trends in the use of specific substances is increasingly difficult (EMCDDA 2005). The same report also suggests that problematic drug use is now, as in the past, closely associated with the use of opiates and injection. Of the two million problematic drug users in the EU-25, 1.3 million are likely to be recent injectors. Between six and 7,000 people die annually in the EU as the direct effect of drug misuse. However, there are suggestions that while the levels of problematic use are at an all time high, they may have stabilised, at least in the EU-15 which is now recording a lower proportion of under 25 overdose deaths than a decade ago. A different picture emerges in the EU-10 where deaths among those under 25 increased between the mid 1990s and the beginning of the new century (EMCDDA 2005).

Homelessness patterns are similarly variable and unstable, reflecting in part changing economic and demographic circumstances and the intermittent effectiveness of shifting policy initiatives. Because of variations in national definitions, FEANTSA (The European Federation of National Organisations Working with the Homeless) eschews the accumulation of European statistics on homelessness, but reports annually on national trends. ${ }^{2}$ These trends indicate that for most EU

\footnotetext{
1 EU-15: Austria, Belgium, Denmark, Finland, France, Germany, Greece, Ireland, Italy, Luxembourg, Netherlands, Portugal, Spain, Sweden, UK. In 2004 the EU was enlarged with the addition of 10 new member countries called the EU-10: Latvia, Lithuania, Estonia, Hungary, Poland, Czech Republic, Slovakia, Slovenia, Malta and Cyprus.

2 The FEANTSA Data Collection Working Group and the European Observatory on Homelessness have developed a 'European Typology for data collection on Homelessness and Housing Exclusion' (ETHOS). See Edgar and Meert 2005.
} 
countries the sex, age, and nationality of homeless people have changed over recent decades with more young people, more women, and more immigrants, the latter increasing especially in the prosperous EU-15 (Edgar and Doherty 2001; Edgar et al. 2002, 2004). Levels of homelessness vary from country to country, with Finland and Denmark, for example, recording reduced or stable numbers, with other countries such as Spain and Portugal recording increases in both urban and rural areas. The high levels of street homelessness in some larger Europe cities have required the introduction of special measures, the so-called rough sleeper initiatives, designed to remove and re-house roofless street sleepers. The British initiatives have apparently been particularly successful, at least in reducing the more visible elements of homelessness on the streets of its major cities (van Rankin 2004).

The complex relationship between homelessness and drug misuse has been the focus of considerable research over the past three decades. ${ }^{3}$ Local and national estimates suggest that in most European countries up to and sometimes over $30 \%$ of homeless people have associated drug addiction problems, with the association being particularly strong among rough sleepers and street homeless populations (Lempens et al. 2003). However, by no means do all homeless people have addiction problems (and not all those with problematic substance use are homeless) and the extent of the problem varies by socio-demographic group and through the lifetime of individuals. Nevertheless, the coincidence of homelessness and substance misuse has led some researchers to conclude that drug misuse, especially when co-related with mental illness, is a major factor in causing homelessness (e.g., Barnes and Burnes 1993). These findings have been challenged (e.g., Fischer and Breakey 1991) and more recently such an easy one-way association has been replaced by an awareness of more subtle and complex relationships. Thus, although addiction can be an indirect cause of homelessness (e.g., leading to job loss or relationship break-up), it is also clear that drug related problems are intensified by homelessness, especially rooflessness, and that the onset of substance misuse is frequently and closely linked with the onset of homelessness (Mojtabai 2005).

\section{Institutional Responsibility for Homelessness and Drug Addiction}

Prior to the 1970s, homelessness and drug misuse were rarely identified as major social problems in Europe. Since that time drugs, and to lesser extent homelessness, have moved onto the political and social agendas of the European Union as well as those of individual European countries. At the European level the creation of the European Monitoring Centre for Drugs and Drug Addiction (EMCDDA) in 1993 and the setting-up of the European Federation of National Organisations working with the Homeless (FEANTSA) in 1989, were symptomatic of these growing concerns. The incentives for the establishment of EMCDDA were the observed changing patterns of drug use in Europe with increases in the use of heroin and injecting, the spread of HIV/AIDS and hepatitis $\mathrm{C}$ and the proliferation of

\footnotetext{
3 e.g., Blid and Gerdner 2006; Børner Stax 2003; Fountain et al. 2003; Horn 1999; Kemp et al. 2006; Neale and Kennedy 2002; Nyamathi and Vasquez 1989; Rowe 2005; Ward 1998.
} 
amphetamines and synthetic drugs such as ecstasy. An important further fillip was the growth of concern about drug and drug related crime and issues of public order linked to drug supply and drug use. EMCDDA is a 'first pillar agency' set up under EU secondary legislation and fully funded by the EU. The mission statement of EMCDDA identifies its primary role as providing the European Union and its member states with up-to-date information of a 'high scientific standard' on the nature of drug use and drug addiction in Europe and on the drug policies adopted in individual countries. To this end it facilitates and encourages the development of common instruments for the measurement of drug use and drug addiction. More generally it sees its mission as raising public and government awareness of the European drug problem.

In contrast to EMCDDA, and symptomatic of the lesser involvement of the EU in homelessness issues, FEANTSA is not a creation of the European Commission, though it does receive core funding from the EU: initially under the auspices of the 1980's Poverty Programmes and latterly through the Community Action Programme created by the European Commission in 2000 following the 1999 Treaty of Amsterdam and the 2000 Lisbon European Council meeting. FEANTSA was set up in 1989 by NGOs working with homeless people and today represents some 100 member organisations from 30 European countries. While FEANTSA works closely with many EU institutions (especially the European Commission and the European Parliament) and has consultative status at the Council of Europe and at the United Nations, it remains a non-government organisation without official EU status. FEANTSA's mission statement is both broader and more ambitious than that of ECMDDA. As well as promoting the collection of data on homelessness and facilitating the exchange of information on good practice, FEANTSA defines its key activities as advocacy, lobbying, and research. To these ends, FEANTSA engages in dialogue with European institutions and national and regional governments to promote the development and implementation of effective measures to fight and prevent homelessness, and to raise public awareness about the problems of homelessness. FEANTSA also supports an independent research organisation, the 'European Observatory on Homelessness,' which evaluates policy, develops statistical instruments for the measurement and collation of data and engages in thematic research activities.

In the context of this paper, a striking feature of the latest EMCDDA annual report (EMCDDA 2005) is the virtual absence of any reference to homelessness. "Homeless/homelessness" is mentioned only four times, and then just in passing. There is no engagement with the topic or consideration of the interaction between substance misuse and homelessness. This neglect seems to be something of a retreat from previously expressed concerns. In its 2003 report, EMCDDA explicitly identified the association between problematic drug dependency and social exclusion in which poor and homeless people were highlighted, along with other vulnerable groups such as ex-offenders and school drop-outs, as particularly at risk from substance misuse. The high rate of drug dependency among homeless people in shelters in Denmark, France, and the Netherlands received special mention in the 2003 report (DrugScope 2004). Similarly, in a further 2003 report on 'Selective Prevention,' homeless immigrants, ethnic minorities, and young people were clearly and explicitly identified as 'at risk' of exposure to problematic drug usage. Indeed, 
this same report expressed some regret about the lack of coordination between medical and social agencies in devising coordinated and coherent action to tackle substance misuse among vulnerable groups such as the homeless (EMCDDA 2003). The neglect of the issue of vulnerability which characterised the EMCDDA 2005 report extends to the recently endorsed EU Drugs Strategy for 2005-2012. This strategy, approved and adopted by the Council of the European Union in December 2004, laudably places considerable emphasis on "prevention, early intervention, treatment, harm reduction, rehabilitation and social integration" (Council of the Europe Union 2004, p. 10), yet omits any consideration of the characteristics of those vulnerable groups which are particularly at risk. Young people are mentioned once, homelessness is not mentioned at all; in contrast crime 'prevention' receives 17 mentions and is the focus of considerable detailed discussion. Driven, it appears, by legalistic and medical concerns, the EU strategy document and its two embedded 4 year Action Plans disappointedly do not take up the challenge voiced by DrugScope (2004) to "mainstream problem drug use within broader social policies" (p. 9).

The record of FEANTSA is considerably better in this respect. Clearly driven by the interests and experiences of its member organisations, the links between health and homelessness have figured prominently among FEANTSA's policy statements, lobbying activities and research agendas in recent times (e.g., FEANTSA n.d.; 2004b, 2005 b, 2005c). However, to date, FEANTSA's interests in the relationship between health and homelessness have focused on the rights to health and on the issue of access to health services: in 2004 FEANTSA set up a 'Health and Social Protection Working Group' and coordinated an international conference in Wroclaw, Poland in October 2006 on 'The right to health is a human right: ensuring access to health for homeless people.' Though mental illness has been the focus of some discussion (FEANTSA 2006), issues of comorbidity and the links between homelessness and substance misuse have been curiously neglected. FEANTSA is a member of the European Public Health Alliance (EPHA), but has no links with EMCDDA.

While EMCDDA and FEANTSA pursue their respective roles with considerable energy and enthusiasm and are prominent and successful organisations in their own fields, there is little or no overlap between the activities of the two organisations. The potential contribution of the EU to the development of policies designed to prevent homelessness among substance misusers is thereby diminished. In 2004, FEANTSA attempted to bridge this divide and called on EMCDDA to develop a research programme with a focus on homeless people. As far as can be judged, the call fell on deaf ears. However, though inter-institutional and agency cooperation seems to be limited, other developments, especially in regard to the emergence of what some have called 'Social Europe' suggest another, albeit less direct, avenue for EU interventions in the treatment and prevention of homelessness and substance misuse.

\section{Homelessness, Health Care, and the 'Open Method of Coordination'}

Founded in the post war boom years as an economic entity, the EU (formerly the European Economic Community), the social competences of the European 
Commission and Parliament were limited by the Treaty of Rome (1957) to those that impinged on matters of market integration, free trade, and the mobility of labour. In the intervening decades with the expansion of the Community from its prosperous heartland to embrace less developed areas of Southern Europe (and latterly those of Eastern and Central Europe), and with the diminution of post war prosperity particularly following the recessions of the 1970s and 1980s, issues of social cohesion and exclusion came more to the fore and were taken up in policy debates. The European Union is now characterised by an altogether greater diversity in which social and spatial, as well as economic, uneven development is clearly manifest. The increasing willingness of the EU to engage with social issues first became apparent with the initiation of the poverty programmes of the 1970s and 1980s. The attachment of a social chapter to the Maastricht Treaty of 1993 and its subsequent formal adoption in Articles 136 and 137 of the 1999 Treaty of Amsterdam, marked further significant milestones in the extension of the competencies of the community into hitherto taboo areas of social policy. At the Lisbon European Council in March 2000, member states took a major step forward in establishing the fight against social exclusion and poverty as a central tenet in the creation of modern Europe ambitiously envisaged as "the most dynamic and competitive knowledge-based economy in the world, capable of sustainable economic growth with more and better jobs and greater social cohesion" (Lisbon European Council 2002, para. 5). At the Lisbon meeting it was agreed that the EU would facilitate the development of social policies among member states through an 'Open Method of Coordination.'

The Open Method of Coordination (OMC) is a new approach to EU governance based on what has been labelled 'soft law' involving the development of benchmarks, guidelines, indicators, and good practice which EU member states are encouraged to adopt voluntarily; there is no compulsion, the aim is convergence, not harmonisation. It has been devised as an instrument to share best practices and increase policy convergence in areas that remain a primary responsibility of national governments but are of concern to the EU as a whole. Initially adopted in relation to economic policy, employment, education, and social exclusion, in 2004 the mechanisms of the OMC were extended to health care (Jassem 2004). Through the $\mathrm{OMC}$, the EU has the opportunity to examine good practice in relation to homelessness (through the social inclusion agenda) and drug use and abuse (through the health care agenda) and the links between them. This is indeed a 'soft' approach to the development of treatment and prevention policies for homelessness among substance users, for it is a procedure for displaying national and local initiatives on the EU stage, not for the development of new EU-based initiatives.

The OMC employs several mechanisms; the two of most relevance to the topic of this paper are the National Action Plans and Peer Reviews. National Action Plans are the basic tool of the OMC. They allow member states to identify their priorities and evaluate policies established in relation to each area under review (e.g., employment, social inclusion). These plans, produced every 2 years, are then analysed by the Commission and the Council; the results, presented in a Joint Report, serve as the basis for making recommendations to member states in respect of their policies. The first round of National Action Plans on Social Inclusion 
(NAPs/Incl) in 2001 demonstrated a considerable unevenness in the quality of reports and particularly in the level of consultation with regard to homelessness and drug use. Indeed, the Social Protection Committee of the European Council (SPC), charged with revising the guidelines for the second round of NAPs/Incl (2003/05), unequivocally stressed the need for member states to explicitly take into account the development of policies,

to assist those who are most marginalised and excluded and who experience particularly severe integration problems. They will vary depending on specific national circumstances, but could include for example women from ethnic minorities, ex-prisoners, drug addicts, the homeless, street children or people discharged from institutions (Social Protection Committee 2003, p. 2emphasis added).

Despite this exhortation, the 2003-2005 NAPs/Incl demonstrated a considerable reluctance to engage with homelessness and substance use problems. For example, whereas the Austrian Plan devoted a whole section to a general consideration of homelessness, the Swedish Plan has no mention of the topic. The National Action Plans have come in for considerable criticism and their value questioned on the grounds that they often exclude mention of vital areas of policy (e.g., homelessness), lack detail, and as a consequence have limited potential as vehicles for the dissemination of good practice. A recent evaluation suggests that to become effective NAPs/Incl need to shift from reporting towards strategic planning, to move beyond description to evaluation, and, importantly, to consult more widely by including agencies of civil society (EPAN (European Anti-poverty Network) 2005).

Peer Reviews, the second mechanism of the OMC considered here, though operating on a smaller scale than the NAPs/Incl, seem to have more potential and have already had some impact in disseminating good practice across the EU. Two reviews of homelessness policies have taken place: the English 'Rough Sleepers Initiative' (van Rankin 2004) and the Danish experiment, skaeve huse til skaeve existenser which provides 'unusual housing for unusual people' (Meert 2005). Peer Reviews are specifically designed to promote the identification and exchange of good practices in the field of social inclusion policies. They are seen as a 'mutual learning process' based on the 'systematic evaluation of good practice and assessment of selected policies or institutional arrangements' (EPAN 2005; n.p). Each peer review is hosted by a member state which presents a selected 'good practice' for review. The reviews are carried out by a team composed of representatives from the European Commission and a selection of other EU countries, plus independent experts. The reviews are designed to ascertain whether and how each reviewed policy, regarded as successful in a national context, can be effectively transferred to other member states.

Of most relevance to this paper is the Peer Review of the Danish programme for the provision of alternative forms of permanent housing for people with unusual lifestyles resulting from problematic substance use. The skaeve huse comes with a limited measure of individual support and benefit. The housing provided is 'suboptimal' with the potential for 'self-build' and departs from the design standards of normal housing. The houses are often located in remote areas on marginal land 
where lifestyle preferences can be indulged without infringing on the general population. The Peer Review concluded that the skaeve huse addresses the "real housing needs of a neglected and marginalised section of the population who, despite support services, have failed to be integrated into conventional housing or into one of the many forms of supported housing that have been created for different target groups" (Meert 2005, p. 10). The FEANTSA shadow review of the Danish experiment was a little more cautious in endorsing the programme, but nevertheless identified the experiment as a programme which, in targeting severely marginalised, long-term rough sleepers, "seeks to create a structure where people experiencing homelessness can live in a safe environment, where support is made available, despite ongoing drug and alcohol use" (FEANTSA 2005a, p. 5). FEANTSA goes on to further endorse the Peer Review process in identifying its potential to examine the use and application of harm-reduction strategies for homeless people with drug related problems. For people experiencing homelessness who have severe addiction problems, helping them to manage this problem in a stable environment can be a vital first step towards addressing wider health needs and other problems (FEANTSA 2005a).

A measure of the success of the Peer Review is the transferability of the programmes under consideration. In the case of the Danish experiment, there are proposals to build skaeve huse in the Netherlands where, until now, it has been illegal to build sub-optimal housing. In June 2005 a meeting took place between civil servants from six ministries, national umbrella organisations of local authorities, mental health organisations, the national association of homeless people and the Association of Housing Corporations, the Foundation for Experimental Housing, and the Dutch Federation of Shelters. At this meeting a plan for alternative housing ('strange housing' in Dutch) was discussed and has subsequently been raised with the Dutch government with the objective of developing new legislation.

In evaluating the development of European strategies for homelessness among people with substance use problems we can conclude that although the language of prevention is being increasingly adopted in discussion and debate at the European level (e.g., ESF(European Science Foundation) 2006; FEANTSA 2004a), the prevention of homelessness among substance users has yet to be clearly manifested among the substantive concerns of the EU. Historically there has been little cooperation within the Commission in regard to these issues, and none between Commission agencies such as EMCDDA and external agencies such as FEANTSA. Since 2000, however, there has been in place an institutional mechanism of governance, the Open Method of Coordination, which facilitates greater cooperation between member states and other interested parties in providing an opportunity to 'showcase' national and local examples of effective strategic approaches and effective programmes of service integration. As national homelessness policies begin to develop a more explicit prevention agenda, so the opportunities for the OMC, especially through Peer Review, to engage with prevention issues should increase. While strategic integration and institutional cooperation remain underdeveloped at the EU level, at the national level some countries, under the banner of homelessness prevention, are developing agency 
cooperation and integration strategies. In the next part of this paper, as an illustration of this theme, we examine some recent developments in Scotland.

\section{Preventing Homelessness and Substance Misuse in Scotland}

In recent years, prevention talk has begun to pervade the UK national discourse on homelessness. With prevention as the primary focus, Government agencies in England and Wales (e.g., Department of Communities and Local Government) and Scotland (e.g., Scottish Executive ${ }^{4}$ ) have commissioned research, provided guidance notes and implemented legislation. Under the terms of the Housing Act (Scotland) 2001, the England and Wales Homelessness Act 2002, and the Homelessness Act (Scotland) 2003, local authorities have been charged with drawing up homelessness strategies focused on prevention. Local authorities, in partnership with other agencies such as housing associations and social work departments, have responded with a variety of programmes embracing housing advice centres, family mediation units, domestic violence support units, and tenancy sustainability and rent deposit schemes (Crane et al. 2004; Davis 2006; Frew 2006; Pawson et al. 2006; ODPM 2003; Scottish Executive 2002; Shelter 2006; Welsh Assembly 2004). Homelessness practice in the UK, however, is still predominantly directed towards management and treatment; preventive policies and programmes are still in their infancy, they have not been adopted universally and, as yet, they lack full evaluation and assessment.

Within the UK, and indeed within the EU, Scotland has arguably some of the most progressive legislation aimed at reducing priority homelessness by half by 2009 and eliminating it by 2012 (Scottish Executive 2005a, b). It is an ambitious programme in which prevention strategies are explicit and central. Recent initiatives provide examples of how prevention strategies are being structured around partnership working between central (the Scottish Executive) and local government as well as between agencies (housing and health), which hitherto have had little experience of working together. Embedded within this programme are specific measures designed to tackle problems of homelessness among substance users.

In August 1999 the Scottish Executive appointed a Homelessness Task Force with a remit "[t]o review the causes and nature of homelessness in Scotland; to examine current practice in dealing with causes of homelessness; and to make recommendations on how homelessness in Scotland can best be prevented and, where it does occur, tackled effectively"' (Scottish Executive 2002, para. 1). ${ }^{5}$ The Task Force made 59 recommendations and in May 2002 established the Homelessness Monitoring Group (HMG) to oversee and support the implementation of the recommendations. Two of the 59 recommendations (44 and 47) related

\footnotetext{
${ }^{4}$ In 1998, under the Scotland Act and following the first elections to the Scottish Parliament, the Scottish Executive assumed devolved powers (from the UK parliament in Westminster) for Scottish health, education, justice, rural affairs, and transport.

5 In 2004-05 there were 57,020 homelessness applications to local authorities in Scotland, a rise of $1 \%$ from the 2003-04 compared to 6\% from 2002-03, suggesting a slowing down in the rate of homelessness increase (Scottish Executive 2006a).
} 
explicitly to links between homelessness and substance misuse. The recommendations of the Task Force were accepted by the Executive and enshrined in the terms of the Housing (Scotland) Act 2001 and the Homelessness (Scotland) Act 2003.

Paralleling the work of the Homelessness Task Force and the Homelessness Monitoring Group, the Scottish National Health Service (NHS) Boards developed action plans for health and homelessness. Following the white paper 'Our National Health: A plan for action, a plan for change' (Scottish Executive 2000), each NHS Board was charged with the task of identifying the action it is taking to tackle homelessness and reduce inequalities. In the guidance on developing action plans issued by the Scottish Executive, NHS Boards were directed "to develop a Health and Homelessness Action Plan as an integral part of the Local Health Plan, in partnership with local authorities, the voluntary sector and homeless people,' and to explicitly "link these plans with Local Authorities' Homelessness Strategies", (Scottish Executive Health Department 2001, p. 6).

These ministerial pronouncements on both health and homelessness demonstrate a clear understanding that effective policies and programmes in relation to tackling homelessness among substance misusers requires close collaboration and synergy of effort between a range of agencies and that this joint work needs to operate at a variety of different geographic scales - the Scottish national scale, the regional scale of the NHS Health Boards and at the local level in each Scottish community (Scottish Executive 2005b). In articulating these ideas and concepts and translating them into practice, the Scottish Executive has clearly taken on board the findings of commissioned research (Quilgars and Pleace 2003).

Implementation of the Scottish health and homelessness strategy has, from the outset, focused on a partnership approach between a variety of agencies. Reflecting on this issue, Sue Irving, Scottish Executive coordinator of the Health and Homelessness Action Plans, explained how:

The Health Boards had to take the lead role, but we asked that the local authorities be involved, in terms of housing, social work, etc. another key partner had to be the voluntary sector. Those Health Boards who had never thought about the needs of homeless people needed the expertise of the voluntary sector, which is much closer to homeless people and is better able to reflect the needs of homeless people (Irving 2003, p. 14).

Irving also acknowledged that, following the directive to develop Health and Homelessness Action Plans, some 'frustrations' were expressed by people who had for years attempted to gain the support of Health Boards in addressing the needs of homeless people and failed (Irving 2003). In this respect, for Irving, the strategic lead provided by the Scottish Executive was vital: "Thinking back to before the policy existed, there were people doing work with homeless people in the health sector, but they were very isolated, very uncoordinated" (Irving 2003, p. 15). However, Ministerial directives, even with the best of commitment, do not always translate into practice and the April 2005 report of the Housing Monitoring Group expressed concerns with regard to drug and alcohol policies. In a review of Drug and Alcohol Teams (DAATs), it was found that there were "very poor links between drug and alcohol planning and homelessness", and further monitoring 
procedures were needed to review the implementation of Health and Homelessness standards (Scottish Executive 2005b, p. 70; see also Scottish Executive 2005c). In November 2005, a Homelessness and Substance Misuse Advisory Group was established with the aim of developing a set of integrated approaches for homeless substance misusers as well as disseminating examples of good practice (Scottish Executive 2005b). We conclude this paper with an examination of a recently launched programme that is seeking to translate the strategic lead given by the Scottish Executive into practice in an attempt to tackle chronic problems of homelessness and substance misuse through the provision of integrated support services.

\section{Fife Homelessness and Substance Misuse Service}

In Scotland, Fife Council has the third highest number of homeless applications, after Edinburgh and Glasgow. In June 2005, Fife reported that 3,631 households had presented as homeless, a decrease of 237 (6\%) from the previous year; however in March 2006, the number of applications was said to be increasing and the Head of the Fife Housing Department called for an urgent review of the Fife Homelessness Strategy (Fife Council 2006; Information and Statistics Division 2005). Misuse of drugs and alcohol are thought to be the main reason for failure to maintain contact with homeless support services such as the Fife Council's Rough Sleeper Initiatives (Fife Homeless Group 2003). The characteristics of substance misuse among homeless people in Fife mirror the national picture and the most prevalent drugs are heroin (or methadone), hashish, cocaine, and alcohol. Under the Housing (Scotland) Act 2001, local authorities have a duty to assess the housing situation of homeless people, provide advice, and offer temporary or permanent accommodation 24 hours after first contact with a homeless person or family. The assessment can take up to 28 days to complete and during this time temporary accommodation is offered in the form of bed and breakfast, furnished or part furnished flats, or in a specialist project for young people. During this time, other services are provided, including substance misuse therapies and support and mental health therapies (Fife Council, n.d.).

As the Scottish Executive's awareness of the extent of homelessness and substance misuse problems has increased, national polices have proliferated. Local agencies, which traditionally operated autonomously and often on a voluntary basis, now find themselves with access to greater funding opportunities but also greater regulation. Key policies from the Scottish Executive are fed down to NHS Fife and Fife Council for implementation. The key local polices are the Fife Homelessness Strategy (Fife Homeless Group 2003) and the Fife Health and Homelessness Action Plan (Fife NHS Board 2002). Responsibility for implementation lies with Fife Council and NHS Fife. There are also local strategic partnerships, supported by the Scottish Executive, aimed at bringing local government, the National Health Service (NHS), and other public agencies, including crime reduction, and voluntary sector agencies, together. These include the Fife Homeless Group and the Drug and Alcohol Action Team (DAAT). In effect, these two agencies aim to co-ordinate the myriad of services available locally in order to reduce duplication and competition, 
facilitate new funding opportunities, and enable agencies to meet Scottish Executive targets.

Following the direction of the Scottish Executive Homelessness Monitoring Group, Fife has developed a Homelessness Strategy. A key aim of the Fife Homelessness Strategy 2003-08, authored by the 13 services comprising the Fife Homeless Group, is to develop a multi-agency service to homeless people at the point of first contact. An example is Home4Good, which operates from three distinct geographical localities in buildings designed to accommodate multiple agencies. These agencies include Fife Council Homeless Persons Officers offering housing support and NHS harm reduction needle exchange. There are other initiatives, such as an outreach worker who coordinates the Rough Sleeping Initiative aimed at preventing and resolving street sleeping. As part of Home4Good, the Community Housing Advice Team (CHAT) leads on the prevention of homelessness, mainly through representation in eviction cases in court and through the provision of education and information to other agencies and to school pupils. Other preventative measures being developed include: working with private landlords and financial institutions to alert Fife Council to evictions and developing discharge protocols for people leaving prison and hospitals, and for young people leaving care and the armed forces (Fife Homeless Group 2003).

Policies in Fife are frequently based on 'bottom-up' growth, rather than in response to strategic, evidence-based and coordinated programmes. Such an approach might seem to run counter to government pronouncements concerning the necessity for evidence-driven policy (Davies et al. 2000), but in the context of current service delivery, the 'bottom-up' approach can be considered an invaluable strength in terms of responding to local need. As at the national level, it is only relatively recently that an integrated approach has been actively developed and supported at the local level. Where statutory services did not provide a service, voluntary sector agencies traditionally stepped in, often working in isolation. An example of this is the Drug and Alcohol Project Levenmouth (DAPL), which provides a specialist counselling service to anyone affected by substance use. DAPL was started by a group of community volunteers in 1993 in response to the rise in drug- related deaths in the area (Denholm 2006). DAPL is now an active member of coordinating groups such as the DAAT, and is part of the newly established Fife Homelessness and Substance Misuse Service.

A priority of homelessness policy in Scotland is the development of links between health and homelessness, in particular substance misuse services and mental health services. In terms of prevention, the Fife Health and Homelessness Action Plan (Fife NHS Board 2002) sets similar targets to that of the Fife Homelessness Strategy: for example, providing a mediation service, developing hospital discharge procedures, promoting independent living skills, and providing assistance to maintain tenancies. Delivery of health and homelessness objectives is achieved through a variety of channels with the aim of providing each client with a care pathway addressing his/her complex housing, health and social care needs (MacKinnon 2004). Services are delivered through 'one-stop-shops,' such as Home4Good's 'drop-in' centre, where a variety of services are available in one location, and by means of 'assertive outreach,' where service providers go out to 
places known to be the habitual locations of homeless people. The organic (bottomup) way in which health and housing services have grown in Fife is a strength in the sense that it is responding to pressing locally identified needs. However, it has led to gaps and unevenness in service provision. These gaps may be in terms of geographic coverage or in terms of the provision of specialist services. For example, of the seventeen services reporting through Fife DAAT on the uptake of substance misuse services, only three had specialist workers or facilities aimed at homeless people and of these three only one had undertaken specific action to attract use by homeless people. To plug these gaps and to enhance the effectiveness of service delivery, a more strategic, integrated approach is required; the Fife Homeless and Substance Misuse Service is an example of such a development. It is also an example of how a strategic approach at the national level can impact on the integration of services at a local level.

In 2005 the Scottish Executive put out a call for funding applications for the development of specialist substance misuse services for homeless people. Fife's Drug and Alcohol Action Team (DAAT 2005a)—one of several such teams set up by the Scottish Executive to lead partnerships working between local authorities, health boards, police forces and agencies in the voluntary sector providing services to substance users-acted as the local mediator in handling and processing applications. The Fife DAAT received three applications: from DAPL (Drug and Alcohol Project, Levenmouth), Clued Up (a drop-in centre for young homeless people) and Fife NHS Addiction Services. Rather than choosing to put forward only one of these bids, the DAAT submitted all three as a new, integrated service (DAAT 2005b). In July 2005, Fife NHS Board was allocated 2-years funding from the Scottish Executive to support assertive drug and alcohol outreach services and therapies targeted at hard-to-reach homeless people. Fife's DAAT, in partnership with local statutory and non-statutory agencies, had responsibility for allocating this funding, a substantial part of which is being used to set-up a new service, the 'Fife Homelessness and Substance Misuse Service,' run in partnership by DAPL, Clued Up, and Fife NHS Addiction Services. The geographical reach of the new integrated service extends to the whole of Fife and provides assertive outreach as well as support at fixed locations, such as at Home4Good and in homeless hostels. Under the new service, DAPL has been allocated two additional counsellors and Clued-Up two additional outreach workers focusing on 16-25 year olds (Crombie 2006). Fife NHS Addiction Services involvement comes in the form of CHANT (The Community Homeless Addiction Nursing Team), a team of three nurses with specialist experience in substance misuse (Mays 2006). Although Home4Good is not explicitly a partner in the current funding, the Manager attends all project planning meetings and has input into service development; Home4Good provides a point for integration between housing and health services in terms of planning, joined-up service delivery, and a physical location at which health services are made available to homeless people when they come in for housing advice. Linked with the implementation of the Fife Homelessness and Substance Misuse Service, the Scottish Executive has provided funding for an additional community psychiatric nurse to work specifically with homeless people in Fife to improve their access to mainstream mental health services. 
Part of Fife Council's Homeless Strategy Action Plan is to provide services that: "place homeless people at the heart of an integrated, seamless response that reduces the harmful effects of homelessness", (Fife Council, 2003, p. 3). Such an aim fits in closely with those of the new service. The Fife Homelessness and Substance Misuse Service started delivery in February 2006 and aims to see 300 homeless people each year. The intention is that most people referred will be seen within 24 hours, and all within 72 hours. Homeless people will have initial contact with a service worker who will work in partnership with a range of agencies in order to stabilise the lives of substance users and sustain housing.

The Fife Homelessness and Substance Misuse Service is an innovative, locally initiated project whose conception was stimulated by the development of a national strategic perspective on health and homelessness. A strategic perspective that not only recognised the need for institutional partnerships within and between government and civil society support agencies, but also provided the resources for their establishment. As a newly integrated service the three member agenciesDAPL, Clued-Up, and Fife NHS Addiction Service-face difficulties across a range of organisational and operational issues: establishing clear joint aims and objectives; overcoming organisational differences; identifying roles and responsibilities; establishing strategic support and commitment; setting up communication systems; providing physical space from which to work and meet as a team; recruitment of specialist personnel; putting in place appropriate professional support; overcoming professional stereotypes; establishing trust and respect; and undertaking joint training (Cameron and Lart 2003). Integration and cooperation between the three services, all accustomed to working on their own with their own routines and targets, has been identified as one of the main operational difficulties and there is ongoing work between the management of the three services and the DAAT to coordinate and define roles within the new service Through the difficult early months of establishing working practices and relationships, front-line staff and managers have remained committed to the ideals of the project in focusing on establishing care pathways for clients that recognise and address the complex linkages between health and homelessness.

The Fife Homelessness and Substance Misuse Service (while recognising that it is still at a beginning stage and has yet to be tested by the passage of time) provides a tangible example of 'joined-up local practice' emanating from 'joined-up strategic planning' which, if successful, has potential as a model for the establishment of similar services elsewhere in Scotland and beyond. However, some caution needs to be expressed with regard to the issue of transferability. In this respect an instructive comparison can be drawn between the Fife Service and the Danish programme skaeve huse til skaeve existenser.

Both the Fife Service and the Danish programme illustrate the effectiveness and desirability of inter-agency working and cooperation in tackling the chronic needs of a marginalised population. In dealing on a day-to-day basis with the combined and complex problems of homelessness and substance misuse, these programmes have adopted an integrated approach and level of agency cooperation that provide a tangible example of a modus operandi palpably absent at the European level where EU institutional sclerosis seems to be the order of the day. However, the differences 
between the Danish experiment and the Fife project are also significant and suggest that some care needs to be taken in arguing for the replication and transferability of these projects across national and regional boundaries to other social contexts. A clear difference between the projects is that the Fife Homelessness and Substance Misuse Service is a one-off, grass-roots initiated local project, whereas the Danish skaeve huse programme is a national initiative, developed by the Danish Ministry for Housing and Construction, with local manifestations. Of more significance, however, is the difference between the projects in the way they conceive of and approach the problem of chronic homelessness and substance misuse. The Fife Service is in this respect an altogether more 'conservative' project that attempts to 'normalise' the marginal group and reintegrate it, individually and collectively, into mainstream society. The Danish programme adopts a more radical stance in conceding to the marginal group the right to live their own lives in the way they desire and in seeking to find a way in which these preferences can be realised without detriment to mainstream society: the Fife Service is inclusive and homogenising; the Danish programme is exclusive and segregationist. These fundamentally different approaches reflect different social and cultural histories and, perhaps, different national values. Meert (2005) reiterates the argument of Busch-Geertsema (2001) in suggesting that the Danish programme needs to be seen in the context of a society that already tolerates the unconventional, especially in relation to housing (see Sørensen 1993). The skaeve huse til skaeve existenser project, which might seem a shocking and extraordinary concession and even an admission of failure in other (perhaps especially Scottish) societies, is in Denmark, with its long history of tolerating alternative lifestyles, unremarkable and commonsensical.

What the EU lacks in land mass it more than makes up for in terms of population size (450 million) and in terms of its diversity of culture and history: 25 separate and autonomous nations, each with their own specific histories and internal social and ethnic regional variations. In these circumstances, local projects developed in local contexts, albeit tackling a universal problem, may not be easily transferable. The Fife Service and the Danish programme have much to offer in demonstrating the benefits of interagency cooperation and integration, but the judgement as to their replicability and transferability to other parts of Europe will be mediated through other and often quite different local social and cultural lenses from those which operate in their place of origin.

\section{Conclusion}

The Fife Homelessness and Substance Misuse Service is a local manifestation of an ambitious Scottish programme designed to eliminate homelessness by 2012. The Fife Service is directed at the chronic end of the homeless/addiction syndrome, targeting a hard-to-reach population whose perceived chaotic life style frequently results in its exclusion from hostel accommodation and addiction therapies; engagement with the Service creates the opportunity, perhaps for the first time, of client access to stable accommodation and positive engagement with treatment regimes. As a proactive interventionist programme designed to capture a hitherto 
largely excluded population, the Fife Service is accurately portrayed as 'crisis management.' To characterise the Service solely in these terms, however, is to diminish its potential longer-term contribution in preventing the reoccurrence of homelessness among a chronically marginalised group. Further, a focus on crisis management ignores the manner in which the Service is embedded in a wider programme of social care delivery which includes not only Fife DAAT, the Fife Homelessness Group and the Community Housing Advice Team (all mentioned previously in this paper), but also the Fife Intensive Outreach Project, which provides support to people with comorbid mental health and substance misuse problems. Each of these services, while having a 'treatment' function, also has a preventative role aimed at early intervention, tackling emerging problems before they evolve into crisis (see Poole and Zuganzaga 2003).

A further preventive dimension of the Fife Homelessness and Substance Misuse Service is its 'action research' component. The experience of delivering the service and the insights gleaned from case studies will yield important evidence regarding the risk factors and trigger events that lead to homelessness among substance misusers. The appointment of a psychiatric nurse in association with establishment of the Fife Service suggests that, from the outset, the programme recognised the common association of substance misuse, homelessness, and mental health problems. The practice of the Service will afford invaluable insight into complex problems of comorbidity providing guidance for effective 'up-stream,' early interventions (Hodges et al. 2006; Scottish Executive 2003). No formal mechanisms have been established for transmitting the evidence derived from the Service and this may yet prove to be a weakness. However, Fife DAAT and the Fife Homelessness Group, which have oversight of the Homelessness and Substance Misuse Service, will provide an informal institutional conduit for evidence transfer facilitating its potential to influence preventive practice. Finally, the innovative nature of the Fife Service marks it out as a likely candidate for European peer review under OMC procedures. The added value of European evaluation is that, as well as disseminating the lessons of the programme to an international audience, it subjects the Fife experiment to comparative evaluation and links the programme to wider appraisal in the context of European debates regarding social exclusion and health and housing rights (Edgar et al. 2002; Kenna 2005; The Scottish Office 1999).

Acknowledgments We would like to thank service providers in Fife for their warm welcome and willingness to engage with our research: Laura Crombie, Martin Denholm, Rita Keyte, Lynda Mays, Mary Millar and the staff of the Fife Homelessness and Substance Misuse Service. We would also like to acknowledge the stimulation and encouragement provided by our colleagues in the Health and Homeless Research Group (HOMAR) at the Universities of St Andrews and Dundee: Iain Atherton, Alex Baldacchino, Roslyn Blair, Chris Dibben, Jennifer Harris, Thilo Kroll and David Manley.

\section{References}

Barnes, A., \& Burnes, D. (1993). A nation in denial. Boulder, CO: Westview Press.

Blid, M., \& Gerdner, A. (2006). Socially excluding housing support to homeless substance misusers: two Swedish case studies of special category housing. International Journal of Social Welfare, 15(2), $162-179$. 
Børner Stax, T. (2003). Estimating the use of illegal drugs among homeless people using shelters in denmark. Substance Use \& Misuse, 38(3-6), 443-462.

Busch-Geertsema, V. (2001). Wohnungslosenpolitik in anderen EU-Ländern. Übertragbarkeit von Konzepten und Maßnahmen auf Deutschland. Studieim Auftrag des Bundesministeriums für Verkehr, Bau und Wohnungswesenvertreten durch das Bundesamt für Bauwesen und Raumordnung [Policies for tackling homelessness in other EU countries-Transferability of concepts and measures to the German situation; Study on behalf of the German Federal Ministry of Transport, Building, and Housing represented by the Federal Office for Building and Regional Planning]. Bielefeld: Germany, Verlag Soziale Hilfe.

Cameron, A., \& Lart, R. (2003). Factors promoting and obstacles hindering joint working: A systematic review of the research evidence. Journal of Integrated Care, 11(2), 9-17.

Council of the European Union. (2004). EU drugs strategy (2005-2012), Brussels. Retrieved May 29, 2006, from http://www.unicri.it/wwk/publications/dacp/legislation/drugs/ sdr\%202005\%2012\%2consiglio\%20europeo\%202005_2012.pdf.

Crane, M., Fu, R., \& Warnes, A. M. (2004). Building homelessness prevention practice: Combining research evidence and professional knowledge. Sheffield, UK: University of Sheffield, Sheffield Institute for Studies on Ageing.

Crombie, L. (2006). Clued up project "Telling it like it is'. Paper presented at Fife Homelessness and Substance Misuse Service, Glenrothes, Fife.

DAAT. (2005a). Corporate action plan 2005-2006. Unpublished Report, Fife, Drug and Alcohol Action Team.

DAAT. (2005b). Allocation of drug treatment and rehabilitation funds. Unpublished Report, Fife, Drug and Alcohol Action Team.

Davies, H., Nutley, S., \& Smith, P. (Eds.) (2000). What works? Evidence based policy and practice in public services. Bristol, UK: The Policy Press.

Davis, S. (2006). Homeless prevention and housing association: Contributing to efficiency. Coventry, UK: Chartered Institute of Housing.

Denholm, M. (2006). The drug and alcohol project levenmouth. Paper presented at Fife Homelessness and Substance Misuse Service, Glenrothes, Fife.

DrugScope. (2004). DrugScope manifesto: European parliamentary elections 2004. Retrieved May 29, 2006, from http://drugscope.org.uk/wip/23/pdfs/euroelect.pdf.

Edgar, B., \& Doherty, J. (2001). Women and homelessness in Europe: Pathways, services and experiences. Bristol, UK: The Policy Press.

Edgar, B., Doherty, J., \& Meert, H. (2002). Access to housing: Homelessness and vulnerability in Europe. Bristol, UK: The Policy Press.

Edgar, B., Doherty, J., \& Meert, H. (2004). Immigration and homelessness in Europe. Bristol, UK: The Policy Press.

Edgar, B., \& Meert, H. (2005). Fourth review of statistics on homelessness in Europe. The ETHOS definition of homelessness. Brussels: FEANTSA.

EMCDDA. (2003). Selective prevention: First overview on the European situation. European Monitoring Centre for Drugs and Drug Addiction, Lisbon. Retrieved May 29, 2006, from, http://www.emcdda.europa.eu/?nnodeid=156.9.

EMCDDA. (2005). The state of the drugs problem in Europe. European Monitoring Committee for Drugs and Drug Addiction. Annual Report, Lisbon. Retrieved May 29, 2006, from http://annualreport.emcdda.europa.eu/en/home-en.html.

EPAN. (2005). Reinforcing the EU inclusion strategy. Report of the Social Inclusion Conference European Anti-Poverty Network, Brussels. Retrieved May 30, 2006, from http://www.eapn.org/ module/module_page/images/pdf/pdf_publication/EAPN\%20Publications/meetings/Luxembourgreport_en.pdf.

ESF. (2006). Developing the EU social scientific evidence base on integrated approaches to prevent and address homelessness. Retrieved September 20, 2006, from http://www.esf.org/esf_article.php?language $=0 \&$ activity $=4 \&$ domain $=5 \&$ article $=579 \&$ page $=1406$.

European Union Working Group. (2000). Implementing the habitat agenda: the European Union experience. Stockholm: Swedish Ministry of Foreign Affairs.

FEANTSA (n.d.). EU policy: Health and homelessness: The programme of community action in the field of public health. Retrieved May 29, 2006, from www.feantsa.org.

FEANTSA. (2004a). Prevention strategies to combat homelessness: A European report. Retrieved September 17, 2006, from www.feantsa.org. 
FEANTSA. (2004b). Meeting the health needs of homeless people. Retrieved May 29, 2006, from www.feantsa.org.

FEANTSA. (2005a). Homelessness in Denmark: “Freak Houses for Freak People” or “Unusual Housing for Unusual Lifestyles',. Shadow Peer Review. Retrieved May 30, 2006, from www.feantsa.org/files/social_inclusion/Peer\%20Review/FR_PeerRev2005_final.pdf.

FEANTSA. (2005b). Pathways to social integration for people with mental health problems: The establishment of social cooperatives in Greece. Retrieved May 29, 2006, from www.feantsa.org.

FEANTSA. (2005c). Tuberculosis and homelessness. Retrieved May 29, 2006, from www.feantsa.org.

FEANTSA. (2006). Contribution to the consultation on the commission Green Paper on Mental Health. Retrieved May 29, 2006, from www.feantsa.org.

Fife Council (n.d.). Fife council homeless advice. Retrieved May 15, 2006, from http://www.fife.gov.uk.

Fife Council. (2006). Homelessness: Review 2005/06 and future challenges. Unpublished Report, Adult Services Committee, Fife Council.

Fife Homeless Group. (2003). Fife homelessness strategy 2003-2008. Fife, Scotland: Fife Council.

Fife NHS Board. (2002). Fife health and homeless action plan, National Health Service Board, Fife. Retrieved May 30, 2006, from http://www.show.scot.nhs.uk/sehd/healthandhomelessness.

Fischer, P. J., \& Breakey, W. R. (1991). The epidemiology of alcohol, drug and mental disorders among homeless persons. American Psychologist, 46(11), 1115-1128.

Fountain, J., Howes, S., \& Strang, J. (2003). Unmet drug and alcohol service needs of homeless people in London: A complex issue. Substance Use and Misuse, 38(3-6), 377-393.

Frew, F. (2006). The role of advice and information in the prevention and alleviation of homelessness in Glasgow. Retrieved September 20, 2006, from http://scotland.shelter.org.uk/policy/policy6489.cfm.

Hodges, C.-L., Paterson, S., Taikato, M., Mgarrol, S., Crome, I., \& Baldacchino, A. (2006). Co-morbid mental health and substance misuse in Scotland. Edinburgh, Scotland: Scottish Executive.

Horn, M. (1999). Drugs and homelessness: Prevalence of alcohol and drug dependence among people experiencing homelessness. Melbourne, Australia: Hanover Press.

Information and Statistics Division. (2005). Drug misuse statistics Scotland 2004. Edinburgh, Scotland: Edinburgh, Information and Statistics Division, NHS.

Irving, S. (2003). Delivering health care to homeless people: An effectiveness review. Research in Brief, No. 13. Edinburgh, Scotland: National Health Service.

Jassem, A. (2004). An introduction to the open method of coordination (OMC). Brussels European Public Health Alliance (EPHA) Briefing Paper. Retrieved May 29, 2006, from http://www.epha.org/IMG/ pdf/EPHA_briefing_on_OMC_AJ_20050216final.pdf.

Kemp, P., Neale, J., \& Robertson, M. (2006). Homelessness among problem drug users: Prevalence, risk factors and trigger events. Health and Care in the Community, 14(4), 319-328.

Kenna, P. (2005). Housing rights and human rights. Brussels: FEANTSA.

Lempens, A., van de Mheen, D., \& Barendregt, C. (2003). Homeless drug users in Rotterdam, The Netherlands: Profile, way of Life, and the need for assistance. Substance Use \& Misuse, 38(3-6), 339-375.

Lisbon European Council. (2002). Presidency conclusion. Retrieved February 13, 2007 from http:// www.bologna-berlin2003.de/pdf/PRESIDENCY_CONCLUSIONS_Lissabon.pdf.

MacKinnon, D. (2004). Delivering health care to homeless people: An effectiveness review Research Brief 13, NHS Scotland. Retrieved January 25, 2006, from http://www.hebs.com/researchcentre/pdf/ Researchinbrief13.pdf.

Mays, L. (2006). Community Homeless Addiction Nursing Team (CHANT). Paper presented at Fife Homelessness and Substance Misuse Service, Glenrothes, Fife.

Meert, H. (2005). Poverty and tackling homelessness: A synthesis report. Retrieved May 30, 2006, from http://www.peer-review-social-inclusion.net/peer/en/index_html.

Mojtabai, R. (2005). Perceived reasons for loss of housing and continued homelessness among homeless persons with mental illness. Psychiatric Services, 56(2), 172-178.

Neale, J., \& Kennedy, C. (2002). Good practice towards homeless drug user: Research evidence from Scotland. Health and Social Care in the Community, 10(3), 196-205.

Nyamathi, A., \& Vasquez, R. (1989). Impact of poverty, homelessness, and drugs on Hispanic women at risk for HIV infection. Hispanic Journal of Behavioral Sciences, 11(4), 299-314.

ODPM. (2003). Prevention of homelessness policy briefing. Retrieved September 20, 2006, from http:// www.communities.gov.uk/. 
Pawson, H., Netto, G., \& Jones, C. (2006). Homelessness prevention: A guide to good practice. London: Department of Communities and Local Government.

Poole, D. L., \& Zugazaga, C. B. (2003). Conceptualizing prevention as the first line of offense against homelessness: Implications for the Federal continuum of care model. The Journal of Primary Prevention, 23(4), 409-424.

Quilgars, D., \& Pleace, N. (2003) Led rather than leading? Research on homelessness in Britain. Journal of Community and Applied Sociology, 13(2), 187-196.

Rowe, J. (2005). Laying the foundations: Addressing heroin use among the street homeless. Drugs: Education, Prevention \& Policy, 12(1), 47-59.

Scottish Executive. (2000). Our national health: A plan for action, a plan for change. White Paper to Scottish Parliament. Edinburgh, Scotland: Scottish Executive.

Scottish Executive. (2002). Helping homeless people: An action plan for prevention and effective response. Edinburgh, Homelessness Task Force Final Report. Edinburgh, Scotland: Scottish Executive.

Scottish Executive. (2003). Mind the gap: Meeting the needs of people with co-occurring substance misuse and mental health problems. Retrieved September 20, 2006, from www.scotland.gov.uk.

Scottish Executive. (2005a). Helping homeless people: Homelessness statement. Edinburgh, Scotland: Scottish Executive.

Scottish Executive. (2005b). Helping homeless people: Delivering the action plan for prevention and effective response. Edinburgh, Scotland: Scottish Executive.

Scottish Executive (2005c). Operation of the homeless persons legislation in Scotland: National and local authority analyses 2004-05. Statistical Bulletin: Housing Series, HSG/2005/6. Edinburgh, Scotland: Scottish Executive.

Scottish Executive. (2006). Homelessness: Applications and assessments. Retrieved September 20, 2006, from http://www.scotland.gov.uk/Home.

Scottish Executive Health Department. (2001). Health and homelessness guidance. Retrieved January 25, 2006, from http://www.scotland.gov.uk/library3/health/hahg-00.asp.

Shelter (2006). Homeless prevention in Scotland-briefing paper. Retrieved September 4, 2006, from www.shelter.org.uk.

Social Protection Committee. (2003). Common outline for the 2003/2005 NAPs/Inclusion. Retrieved May 30, 2006, from http://ec.europa.eu/employment_social/soc-prot/soc-incl/commonoutline2003final_en.pdf.

Sørensen, P. L. (1993). “Drommennes Port'. Undersogelse af usoedvanlige boligomrader [Drommennnes Port: The phenomenon of unconventional housing forms and localities]. Kopenhagen: SUS, Socialt udviklingscenter Storkobenhavn.

The Scottish Office. (1999). Social inclusion-opening the door to a better Scotland. Retrieved September 20, 2006, from http://www.scotland.gov.uk/library/documents-w7/sima-00.htm.

van Rankin, J. (2004). The English rough sleeping strategy in a European context. Retrieved May 30, 2006, from http://www.peer-review-social-inclusion.net/peer/en/index_html.

Ward, J. (1998). Substance use among young people 'looked after' by social services. Drugs: Education, Prevention and Policy, 5(3), 257-269.

Welsh Assembly. (2004). Prevention of homelessness advice note. Cardiff, Wales: Welsh Assembly Government. 